\title{
Type 1 Diabetes Outcomes: Does Distance to Clinic Matter?
}

Danya A. Fox ${ }^{1}$ MD, Nazrul Islam ${ }^{2} \mathrm{PhD}$, Shazhan Amed ${ }^{1} \mathrm{MD}$

${ }^{1}$ Department of Pediatrics, University of British Columbia, Vancouver, BC, Canada

${ }^{2}$ MRC Epidemiology Unit, University of Cambridge, Cambridge, UK

Shazhan Amed (Corresponding Author)

K4-206, 4480 Oak Street

Vancouver, BC, Canada, V6H 3V4

Tel: (604) 875-2117; Fax: (604) 875-3231

samed@cw.bc.ca

This article has been accepted for publication and undergone full peer review but has not been through the copyediting, typesetting, pagination and proofreading process, which may lead to differences between this version and the Version of Record. Please cite this article as doi: $10.1111 /$ pedi.12749

This article is protected by copyright. All rights reserved. 


\begin{abstract}
$\underline{\text { ABSTRACT }}$
Background and Objectives: To access care, pediatric type 1 diabetes (T1D) patients living in British Columbia (BC), Canada, travel to the sole tertiary pediatric hospital (BC Children's Hospital; $\mathrm{BCCH})$, or they receive community care from pediatric endocrinologists and/or pediatricians. We sought to determine whether $\mathrm{HbA}_{1 \mathrm{C}}$ and patient reported outcomes were associated with (i) distance to clinic and (ii) tertiary vs. community care.
\end{abstract}

Methods: Patients were recruited from T1D clinics across BC. Clinical chart review and patient surveys were completed, including the Diabetes Treatment Satisfaction Questionnaire (DTSQ). Clinic type was categorized as tertiary $(\mathrm{BCCH})$ or community, and travel time to $\mathrm{BCCH}$ was categorized as $<1$ hour (h), 1-2h, or $>2 h$.

$\underline{\text { Results: }}$ There were 189 participants. Age and duration of T1D were similar across groups. Mean number of visits/year for BCCH groups were 2.23, 2.24 and 2.05 for the $<1 \mathrm{~h}, 1-2 \mathrm{~h}$ and $>2 \mathrm{~h}$ groups, respectively, vs. 3.26 for the community group. Adjusted mean difference in $\mathrm{HbA}_{1 \mathrm{C}}$ was $+0.65 \%(95 \% \mathrm{CI} 0.15,1.15)$ and $+0.52 \%(95 \% \mathrm{CI} 0.02,1.02)$ for the $\mathrm{BCCH}>2 \mathrm{~h}$ group compared to $\mathrm{BCCH}<1 \mathrm{~h}$ group and community group, respectively. Child DTSQ scores were significantly lower in the $\mathrm{BCCH}>2 \mathrm{~h}$ group compared to the $\mathrm{BCCH}<1 \mathrm{~h}$ and community groups. Conclusions: Children travelling $>2 \mathrm{~h}$ to $\mathrm{T} 1 \mathrm{D}$ clinic at $\mathrm{BCCH}$ had significantly higher $\mathrm{HbA}_{1 \mathrm{C}}$ values and lower satisfaction with care versus those travelling $<1 \mathrm{~h}$ to $\mathrm{BCCH}$ and those receiving community care. Access to care closer to home may benefit glycemic control in children with T1D and improve treatment satisfaction. Future research should determine whether these findings can be replicated in other regions.

Key Words: Diabetes mellitus, type 1; Pediatrics; Delivery of health care; Patient satisfaction; Health care quality, access, and evaluation

This article is protected by copyright. All rights reserved. 


\section{$\underline{\text { Introduction }}$}

Pediatric type 1 diabetes (T1D) guidelines recommend that children receive care from a multidisciplinary diabetes team ${ }^{1}$. In British Columbia (BC), a Canadian province over 2 times the size of California, patients often travel long distances to attend the only tertiary T1D clinic located at BC Children's Hospital (BCCH) in Vancouver, Canada. Some children receive T1D care in their local community via outreach by pediatric endocrinologists and/or local pediatric endocrinologists and pediatricians.

In adults with type 2 diabetes, greater distance to care has been associated with higher hemoglobin $\mathrm{A} 1_{\mathrm{C}}\left(\mathrm{HbA}_{1 \mathrm{C}}\right)^{2,3}$. A study of adult patients with T1D found no such relationship; however, they only included patients living in an urban center ${ }^{4}$. The relationship between $\mathrm{HbA}_{1 \mathrm{C}}$ and distance to clinic has yet to be investigated in pediatric T1D and there is limited research comparing outcomes in children receiving community vs. tertiary care ${ }^{4}$. Understanding the impact of distance to clinic and tertiary vs. community care is critical to informing health system transformation for childhood diabetes. We sought to determine whether $\mathrm{HbA}_{1 \mathrm{C}}$ and patient reported outcomes (such as adherence to treatment, satisfaction with care, and barriers to accessing care) were associated with (i) distance to clinic and (ii) tertiary vs. community care. We hypothesized that clinical outcomes and patient reported outcomes would be superior for children receiving care closer to home. For patients accessing care close to home, we predicted that clinical outcomes and patient reported outcomes would be similar, regardless of whether they were receiving tertiary or community care.

This article is protected by copyright. All rights reserved. 


\section{$\underline{\text { Methods }}$}

Patients were recruited from T1D clinics across BC. Inclusion criteria included: (i) physiciandiagnosed T1D after 1-year of age and (ii) duration of T1D for 3 or more years. Patients received a letter of invitation in the mail prior to their clinic appointment. At their clinic appointment, patients who met the inclusion criteria and their parents were approached by a research assistant requesting participation. Aiming for an even representation of the range of patient circumstances, we analyzed the demographic features of the participants on a quarterly basis and used this information to target recruitment at specific clinics. Informed consent was obtained from all participants prior to the completion of surveys. At $\mathrm{BCCH}, 172(30 \%)$ patients consented to participate out of 578 that were approached. This data was unavailable for community sites.

Clinical data were collected by medical chart review. Patient-level data were collected through caregiver surveys, including demographic information. Participants were asked to identify reasons that make it difficult to attend diabetes clinic appointments (barriers to care). They were provided with a list of options and asked to select all statements that applied (see supplemental online material). Odds ratios of reporting a barrier were calculated based on the first response option - 'It isn't difficult to take my child to diabetes clinic appointments.' To validate the main outcome variable, if someone reported they had no barriers based on this first option but then went on to select a barrier from the subsequent choices, they were re-classified as having a barrier $(n=8)$. Of note, there was also an opportunity to record barriers not identified on the list using free text. The list of barriers was devised a priori by the research team and was reviewed with the diabetes team at $\mathrm{BCCH}$ and pediatric diabetes clinicians from diabetes centres across the province. The survey was pilot tested with a small sample of patients to ensure the questions 
were easy to understand prior to its implementation. Feedback from clinicians and patients was integrated.

Clinic type was categorized as tertiary $(\mathrm{BCCH})$ or community, based on self-reported primary diabetes physician. Some patients saw more than one provider for their diabetes care; however, their categorization was always based on their self-selected primary doctor. As reported by the caregivers, travel time to $\mathrm{BCCH}$ was categorized as: $<1$ hour $(\mathrm{h}), 1-2 \mathrm{~h}$, or $>2 \mathrm{~h}$. The average of the last three $\mathrm{HbA}_{1 \mathrm{C}}$ values was compared across the 3 aforementioned $\mathrm{BCCH}$ groups and the community group.

Parents were asked to complete the Diabetes Treatment Satisfaction Questionnaire (DTSQ) ${ }^{5}$, a 13-item survey that explores satisfaction with various aspects of diabetes treatment, current glycemic control, and support from the diabetes care team. Responses range from 'very dissatisfied' to 'very satisfied' on a scale from 0 to $6^{5}$. An overall treatment satisfaction score is calculated as the sum of responses to 10 of the survey items, resulting in a maximum total score of 60. As per the scoring instructions, three of the items were not included in the total score, as they evaluated domains other than treatment satisfaction. Finally, families were asked to fill out the Adherence in Diabetes Questionnaire (ADQ) ${ }^{6}$. There are 4 parental versions of this survey with 17-19 questions, tailored to the age of the child (2-4 years or 5-18 years) and insulin regimen (conventional treatment or insulin pump.) The questionnaire evaluates self-perceived adherence to diabetes management, including insulin, diet, blood glucose monitoring, treatment of hypoglycemia/hyperglycemia, physical activity, and attendance at clinic appointments ${ }^{6}$.

Responses ranged from 'not at all' (1) to 'always' (5). The final score is computed as the mean

This article is protected by copyright. All rights reserved. 
of all the items, with a score of 5 indicating the highest level of adherence ${ }^{6}$. Children were also offered the opportunity to complete the youth versions of the DTSQ and ADQ, age-permitting. The DTSQ teen satisfaction score includes responses to 8 items (maximum score 48$)^{5}$. The child ADQ format is similar to the parent survey, with 17-19 questions depending on insulin regimen ${ }^{6}$.

Descriptive statistics are presented in terms of number and percentage for categorical variables, and mean and standard deviation (SD) for continuous variables. For the regression analysis, covariates were selected a-priori to control for confounding using causal inference methodology. Those significant at the 0.15 level in the unadjusted analyses were added to the multivariable regression models (linear regression for the continuous outcomes, and logistic regression for the binary outcome (yes/no) of reporting any barrier to attending clinic). Stata 14.2 was used for all the statistical analyses, and all the tests were 2-sided at 0.05 levels of significance ${ }^{7}$.

The University of British Columbia Children's \& Women's Research Ethics Board approved the study.

\section{$\underline{\text { Results }}$}

Table 1 summarizes patient characteristics. Among community patients, 77\% (56/73) received care from a pediatric endocrinologist, of which $22 \%$ were seen by pediatric endocrinologists working at $\mathrm{BCCH}$ and providing community-based outreach, and the remainder by pediatric endocrinologists working in the community. Twenty-three percent (17/73) received care from pediatricians. Eighty-eight percent of the community group travelled less than one hour to see their diabetes care provider. Patients' age and diabetes duration were comparable across groups (Table 1). As outlined in Table 1, community patients were seen in clinic more often compared 
to tertiary patients (approximately 1 extra visit per year, on average). Insulin regimen differed across the groups, with more children utilizing continuous subcutaneous insulin infusions (CSII) in the community group. Parent and teen ADQ scores were similar across the groups.

Twenty-three percent of community patients and $18 \%, 32 \%$, and $45 \%$ of tertiary patients travelling $<1 \mathrm{~h}, 1-2 \mathrm{~h}$, and $>2 \mathrm{~h}$, respectively, reported $\geq 1$ barriers to attending clinic. Distance to clinic was the most common barrier, followed by time off work (Figure 1). Compared to community patients, tertiary patients travelling $>2 \mathrm{~h}$ had over 3 times higher odds of reporting barriers to attending clinic (odds ratio 3.46; 95\% CI: 1.17, 10.25; adjusted for household income) (Table 2). There were no significant differences for the parental DTSQ scores between groups, after adjusting for age and household income. However, analysis of the child DTSQ scores showed notable differences. When compared to the tertiary $<1 \mathrm{~h}$ group, the tertiary $>2 \mathrm{~h}$ group had significantly lower DTSQ scores (score difference -7.24; 95\% CI: $-11.86,-2.63, \mathrm{p}=0.003$ ) (Table 3). Similarly, when compared to the community group, the tertiary $>2 \mathrm{~h}$ group again had significantly lower satisfaction (score difference -6.37 ; 95\% CI -11.04, $-1.70, \mathrm{p}=0.008$ ). Of note, there was no adjusted analysis for the child DTSQ scores, as no factors were found to be significant at the 0.15 level in the univariate analysis. Finally, mean $\mathrm{HbA}_{1 \mathrm{C}}$ was significantly higher in the tertiary $>2 \mathrm{~h}$ group compared to tertiary $<1 \mathrm{~h}$ group (adjusted difference in $\mathrm{HbA}_{1 \mathrm{C}}$ : $0.65 \% ; 7.1 \mathrm{mmol} / \mathrm{mol}, 95 \% \mathrm{CI}: 0.15,1.15 \% ; 1.6,12.6 \mathrm{mmol} / \mathrm{mol}, \mathrm{p}=0.01]$ and community group (adjusted difference in $\mathrm{HbA}_{1 \mathrm{C}}: 0.52 \% ; 5.7 \mathrm{mmol} / \mathrm{mol}, 95 \% \mathrm{CI}: 0.02,1.02 \% ; 0.2,11.1 \mathrm{mmol} / \mathrm{mol}$, $\mathrm{p}=0.04]$ (Table 4).

$\underline{\text { Discussion }}$

This article is protected by copyright. All rights reserved. 
Despite similar patient demographics and self-reported treatment adherence, children travelling $>2 \mathrm{~h}$ to attend a tertiary T1D clinic had significantly higher mean $\mathrm{HbA}_{1 \mathrm{C}}$, increased perceived barriers to care, and lower satisfaction with treatment compared to those travelling $<1 \mathrm{~h}$ and those receiving care in their local community. Patients receiving community care had similar patient reported outcomes and $\mathrm{HbA}_{1 \mathrm{C}}$ compared to those traveling $<2 \mathrm{~h}$ to access tertiary care.

To our knowledge, we are the first to demonstrate the impact of travel time on pediatric type 1 diabetes outcomes. The reason for this discrepancy in outcomes is unknown. All tertiary patients had 24-hour access to an on-call endocrinologist in case of emergencies, and access to nursing support on weekdays via email, fax and phone, regardless of their location. However, it is possible that the families travelling $>2 \mathrm{~h}$ to attend a tertiary diabetes clinic felt less connected to their care team, and thus did not utilize these services as frequently as patients residing closer to $\mathrm{BCCH}$. Unfortunately, these healthcare encounters are often not recorded, preventing us from evaluating this hypothesis. Another possible explanation for the discrepancy in outcomes between the $\mathrm{BCCH}$ groups may be related to support provided by other physicians. Patients living outside of Vancouver and the surrounding area may have limited access to family physicians and pediatricians. However, this would not explain the differences in outcomes between the $\mathrm{BCCH}>2 \mathrm{~h}$ group and the community group.

Consistent with prior research, we found that community patients visited clinic more often than tertiary patients ${ }^{4}$. This may have contributed to the differences in $\mathrm{HbA}_{1 \mathrm{C}}$ between the community and $>2 \mathrm{~h}$ tertiary group, yet it would not account for the differences between the $<1 \mathrm{~h}$ and $>2 \mathrm{~h}$ tertiary groups, as they had a similar number of visits per year. The differences cannot be

This article is protected by copyright. All rights reserved. 
attributed to the use of CSII, as the BCCH 1-2 hour group had the lowest percentage of CSII patients and despite this, the mean $\mathrm{HbA}_{1 \mathrm{C}}$ in this group was similar to the $\mathrm{BCCH}<1 \mathrm{~h}$ and community groups. Furthermore, the discrepancy in outcomes is unlikely to be the result of a referral bias to the tertiary care center. As highlighted earlier, $77 \%$ of community patients were receiving care from a pediatric endocrinologist, and it is not common practice for these subspecialists to refer complex patients to $\mathrm{BCCH}$, unless they are in need of other sub-specialty services. In addition to distance to care, there may be unknown confounders that could help to explain this discrepancy in outcomes for children traveling longer to access diabetes care.

Further research focusing on patient-reported outcomes should explore what other factors may be contributing to our findings.

Though the association between travel time to clinic and pediatric type 1 diabetes outcomes has not been previously explored, other investigators have compared the outcomes for patients seen at tertiary care centers and those seen in outreach clinics. In Australia, Joshi et al. found that $\mathrm{HbA}_{1 \mathrm{C}}$ was similar in both groups, as were rates of diabetic ketoacidosis ${ }^{8}$. Another Australian study investigated the same issue, and also found comparable $\mathrm{HbA}_{1 \mathrm{C}}$ values over a 6 year period in the tertiary and outreach patients ${ }^{4}$. In their model of care, outreach was provided by a pediatric endocrinologist who worked with the local diabetes care team, including a nurse educator and dietitian ${ }^{4}$. Cameron et al. compared glycemic control for patients seen in a tertiary center compared to regional clinics ${ }^{9}$. The median $\mathrm{HbA}_{1 \mathrm{C}}$ values were higher in the regional clinics; however, the differences were not statistically significant, likely related to the small sample sizes at the regional clinics $(n=13-18)$. Different from our study, the regional patients were primarily

This article is protected by copyright. All rights reserved. 
managed by general practitioners and pediatricians ${ }^{9}$. Satisfaction with care was not formally assessed in the aforementioned studies.

One of the major strengths of this study was our use of patient-reported travel time rather than distance to clinic. This is particularly important in BC, as our geography is highly variable. Another strength was our ability to incorporate caregiver perspectives on barriers to care. Limitations included our smaller sample size for the groups traveling $1-2 \mathrm{~h}$ and $>2 \mathrm{~h}$ to BCCH. We also recognize that the $\mathrm{HbA}_{1 \mathrm{C}}$ results were run on different assays. However, all labs in $\mathrm{BC}$ conform to the National Glycohemoglobin Standardization Program guidelines ${ }^{10}$. Finally, patients were not involved in the development of the list of barriers, a further limitation of this study.

\section{Conclusion}

Our findings suggest that T1D patients traveling long distances to clinic would benefit from care closer to home. Community care has the potential to improve glycemic control, reduce barriers to accessing medical services, and enhance satisfaction with care. This information can be used to re-evaluate current policies related to T1D models of care. With these results, decision-makers can advocate for resources to expand outreach efforts and enhance local capacity to deliver T1D care, bolstering providers ability to deliver high quality, community-based care. Further research should explore whether these findings can be replicated in other geographic and health system contexts and why care closer to home is associated with better $\mathrm{HbA}_{1 \mathrm{C}}$ and satisfaction with care.

This article is protected by copyright. All rights reserved. 


\section{$\underline{\text { Acknowledgments }}$}

We thank the patients and families who took the time to complete the surveys and participate in this research project. We also thank Jeffrey Bone who assisted with the data analysis. All authors were involved in the analysis plan, contributed to the data interpretation, and edited the manuscript. D.F. prepared the first draft of the manuscript. N.I. conducted the data analysis. All authors approved the final version of the manuscript and are accountable for all aspects of the work.

Guarantor Statement: We confirm that the authors do not have any conflicts of interest to declare, real or perceived. This research was supported by Diabetes Canada (formerly Canadian Diabetes Association).

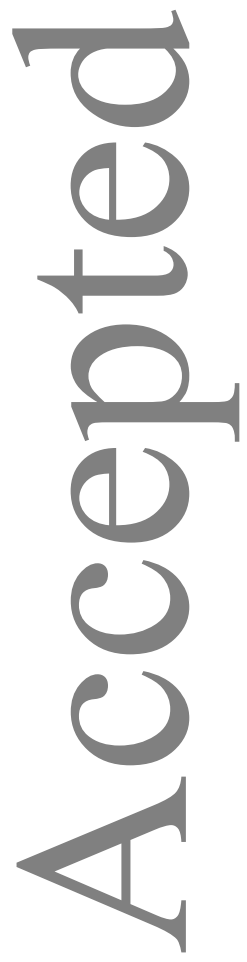

This article is protected by copyright. All rights reserved. 


\section{REFERENCES:}

1. Pihoker C, Forsander G, Fantahun B, et al. The delivery of ambulatory diabetes care to children and adolescents with diabetes. Pediatr Diabetes. 2014;15(S20):86-101. doi:10.1111/pedi.12181.

2. Strauss K, MacLean C, Troy A, Littenberg B. Driving distance as a barrier to glycemic control in diabetes. J Gen Intern Med. 2006;21(4):378-380. doi:10.1111/j.15251497.2006.00386.x.

3. Zgibor JC, Gieraltowski LB, Talbott EO, Fabio A, Sharma RK, Hassan K. The association between driving distance and glycemic control in rural areas. J Diabetes Sci Technol. 2011;5(3):494-500. doi:10.1177/193229681100500304.

4. Simm PJ, Wong N, Fraser L, et al. Geography does not limit optimal diabetes care: Use of a tertiary centre model of care in an outreach service for type 1 diabetes mellitus. $J$ Paediatr Child Health. 2014;50(6):471-475. doi:10.1111/jpc.12499.

5. Bradley C (1994) The Diabetes Treatment Satisfaction Questionnaire: DTSQ. In Bradley C (Ed) Handbook of Psychology and Diabetes: a guide to psychological measurement in diabetes research and practice. Abingdon: Routledge ISBN 9783718655625, formerly published by Harwood Academic Publishers ISBN 3- 7186-5562-4: p.111-132.

6. Kristensen LJ, Thastum M, Mose AH, Birkebaek NH, Danish Society for Diabetes in Childhood and Adolescence. Psychometric evaluation of the adherence in diabetes questionnaire. Dia Care. 2012;35(11):2161-2166. doi:10.2337/dc11-2342.

This article is protected by copyright. All rights reserved. 
7. StataCorp. 2015. Stata Statistical Software: Release 14. College Station, TX: StataCorp LP.

8. Joshi KK, Haynes A, Smith G, Jones TW, Davis EA. Comparable glycemic outcomes for pediatric type 1 diabetes patients in metropolitan and non-metropolitan regions of Western Australia: A population-based study. Pediatr Diabetes. 2017;15(suppl 20):86-87. doi:10.1111/pedi.12550.

9. Cameron FJ, Clarke C, Hesketh K, et al. Regional and urban Victorian diabetic youth: clinical and quality-of-life outcomes. J Paediatr Child Health. 2002;38(6):593-596.

10. Little RR, Rohlfing CL, Sacks DB, National Glycohemoglobin Standardization Program (NGSP) Steering Committee. Status of hemoglobin A1c measurement and goals for improvement: from chaos to order for improving diabetes care. Clinical Chemistry. 2011;57(2):205-214. doi:10.1373/clinchem.2010.148841.

This article is protected by copyright. All rights reserved. 
Table 1: Patient and family characteristics by community and tertiary hospital, stratified by travel time to the tertiary hospital

\begin{tabular}{|c|c|c|c|c|c|c|c|c|}
\hline Characteristics & \multicolumn{2}{|c|}{$\begin{array}{c}\text { BCCH }<1 \mathrm{~h} \\
(\mathrm{n}=71)\end{array}$} & \multicolumn{2}{|c|}{$\begin{array}{c}\text { BCCH 1-2h } \\
(n=25)\end{array}$} & \multicolumn{2}{|c|}{$\begin{array}{c}\text { BCCH }>2 \mathrm{~h} \\
(\mathrm{n}=20)\end{array}$} & \multicolumn{2}{|c|}{$\begin{array}{l}\text { Community } \\
\qquad(n=73)\end{array}$} \\
\hline Age (years); mean (SD) & \multicolumn{2}{|c|}{$12.13(3.81)$} & \multicolumn{2}{|c|}{$12.04(3.79)$} & \multicolumn{2}{|c|}{$12.50(3.15)$} & \multicolumn{2}{|c|}{$12.70(3.3)$} \\
\hline Male; $\mathrm{N}(\%)$ & \multicolumn{2}{|c|}{$40(56)$} & \multicolumn{2}{|c|}{$14(56)$} & \multicolumn{2}{|c|}{$7(35)$} & \multicolumn{2}{|c|}{$33(45)$} \\
\hline \multicolumn{9}{|l|}{ Person completing survey; N (\%) } \\
\hline Mother/step or foster mother & \multicolumn{2}{|c|}{$56(79)$} & \multicolumn{2}{|c|}{$18(72)$} & \multicolumn{2}{|c|}{$19(95)$} & \multicolumn{2}{|c|}{$56(77)$} \\
\hline Father/step or foster father & \multicolumn{2}{|c|}{$9(13)$} & \multicolumn{2}{|c|}{$4(16)$} & \multicolumn{2}{|c|}{$1(5)$} & \multicolumn{2}{|c|}{$13(18)$} \\
\hline Other/no response & \multicolumn{2}{|c|}{$6(8)$} & \multicolumn{2}{|c|}{$3(12)$} & \multicolumn{2}{|c|}{$0(0)$} & \multicolumn{2}{|c|}{$4(5)$} \\
\hline Caucasian; N (\%) & \multicolumn{2}{|c|}{$53(75)$} & \multicolumn{2}{|c|}{$19(76)$} & \multicolumn{2}{|c|}{$19(95)$} & \multicolumn{2}{|c|}{$61(84)$} \\
\hline T1D duration (years); mean (SD) & \multicolumn{2}{|c|}{$6.24(3.49)$} & 5.96 & .82) & 5.40 & & 5.53 & .05) \\
\hline T1D visits/year; mean (SD) & 2.23 & $.75)$ & 2.24 & 70) & 2.05 & & 3.26 & 97) \\
\hline Parental Education; N (\%) & M & $\mathrm{F}$ & M & $\mathrm{F}$ & M & $\mathrm{F}$ & M & $\mathrm{F}$ \\
\hline$\leq$ High school & $8(11)$ & $15(21)$ & $5(20)$ & $5(20)$ & $0(0)$ & $4(20)$ & $15(21)$ & $19(26)$ \\
\hline Post-secondary certificate & $12(17)$ & $11(15)$ & $7(28)$ & $7(28)$ & $10(50)$ & $5(25)$ & $23(32)$ & $19(26)$ \\
\hline College/university & $29(41)$ & $22(31)$ & $6(24)$ & $7(28)$ & $5(25)$ & $5(25)$ & $19(26)$ & $16(22)$ \\
\hline Professional degree & $22(31)$ & $23(32)$ & $6(24)$ & $6(24)$ & $5(25)$ & $5(25)$ & $15(21)$ & $12(16)$ \\
\hline Unknown & $0(0)$ & $0(0)$ & $1(4)$ & $0(0)$ & $0(0)$ & $1(5)$ & $1(1)$ & $7(10)$ \\
\hline Household Income; N (\%) & & & & & & & & \\
\hline$<\$ 70,000$ & & & & & 7( & & 24 & \\
\hline$\$ 70,000-\$ 99,999$ & & & & & 3 & & 16 & \\
\hline$>\$ 100,000$ & & & & & 9( & & 27 & \\
\hline Unknown & & & & & & & & \\
\hline Insulin regimen; $\mathrm{N}(\%)$ & & & & & & & & \\
\hline Injections 2-3x/day & & & & & & & & \\
\hline MDI & & & & & 3 & & 9 & \\
\hline CSII & & & & & 10 & & 60 & \\
\hline ADQ Score & & & & & & & & \\
\hline Parent; mean (SD) & 3.92 & .76) & 4.09 & .59) & 3.98 & 72) & 3.92 & .69) \\
\hline
\end{tabular}




\begin{tabular}{|c|c|c|c|c|}
\hline Child; mean (SD)* & $4.20(0.45)$ & $3.91(0.63)$ & $4.04(0.59)$ & $4.19(0.49)$ \\
\hline \multicolumn{5}{|l|}{ DTSQ Score } \\
\hline Parent; mean (SD) & $46.41(6.14)$ & 44.88 (11.19) & $42.50(7.86)$ & $45.11(8.42)$ \\
\hline Child; mean (SD) ${ }^{* *}$ & $39.80(5.86)$ & $39.89(6.83)$ & $32.56(7.47)$ & $38.93(5.60)$ \\
\hline \multicolumn{5}{|l|}{$\mathrm{HbA}_{1 \mathrm{c} ;}$ mean $(\mathrm{SD})$} \\
\hline$\%$ & $7.88(1.01)$ & $8.16(1.13)$ & $8.64(1.18)$ & $8.15(0.86)$ \\
\hline $\mathrm{mmol} / \mathrm{mol}$ & $63(11.0)$ & $66(12.4)$ & $71(12.9)$ & $66(9.4)$ \\
\hline
\end{tabular}

ADQ: Adherence in Diabetes Questionnaire; BCCH: British Columbia Children's Hospital; CSII: continuous subcutaneous insulin infusion; DTSQ: Diabetes Treatment Satisfaction Questionnaire; F: father; M: mother; MDI = multiple daily injections; SD: standard deviation; T1D = type 1 diabetes

*Sample size: $\mathrm{BCCH}<1 \mathrm{~h}, \mathrm{n}=40$; $\mathrm{BCCH} 1-2 \mathrm{~h}, \mathrm{n}=15$; $\mathrm{BCCH}>2 \mathrm{~h}, \mathrm{n}=15$; community, $\mathrm{n}=40$ **Sample size: $\mathrm{BCCH}<1 \mathrm{~h}, \mathrm{n}=30 ; \mathrm{BCCH} 1-2 \mathrm{~h}, \mathrm{n}=9 ; \mathrm{BCCH}>2 \mathrm{~h}, \mathrm{n}=9$; community, $\mathrm{n}=27$

This article is protected by copyright. All rights reserved. 
Table 2: Adjusted odds ratio of reporting barriers to accessing care comparing tertiary groups (BCCH; stratified by travel time) and community group from multivariate logistic regression

Unadjusted odds ratio

$(95 \% \mathrm{CI})$
Adjusted odds ratio

$(95 \% \mathrm{CI})^{*}$ p-value

$\begin{array}{llcl}2.10(0.75,5.90) & 0.16 & 1.46(0.47,4.53) & 0.51 \\ 3.65(1.26,10.61) & 0.02 & 3.74(1.24,11.31) & 0.02 \\ 1.35(0.60,3.04) & 0.46 & 1.08(0.45,2.58) & 0.86\end{array}$

$0.74(0.33,1.66)$

0.46

$0.93(0.39,2.21)$

0.86

$1.55(0.57,4.22)$

0.39

$2.70(0.96,7.59)$ p-value

BCCH 1-2h

$\mathrm{BCCH}>2 \mathrm{~h}$

*Adjusted for parental income

This article is protected by copyright. All rights reserved. 
Table 3: Differences in parent and child diabetes treatment satisfaction scores between tertiary groups (BCCH; stratified by travel time) and community group from linear regression models (scores from the Diabetes Treatment Satisfaction Questionnaire)

\begin{tabular}{|c|c|c|c|c|c|c|}
\hline & $\begin{array}{c}\text { Parent Score } \\
\text { Unadjusted } \\
\text { difference (95\% } \\
\text { CI) }\end{array}$ & $\begin{array}{c}\text { p- } \\
\text { value }\end{array}$ & $\begin{array}{l}\text { Parent Score } \\
\text { Adjusted } \\
\text { difference } \\
(95 \% \mathrm{CI})^{*}\end{array}$ & $\begin{array}{c}\text { p- } \\
\text { value }\end{array}$ & $\begin{array}{c}\text { Child Score } \\
\text { Unadjusted } * * \\
\text { difference (95\% } \\
\text { CI) }\end{array}$ & $\begin{array}{c}\text { p- } \\
\text { value }\end{array}$ \\
\hline \multicolumn{7}{|c|}{ Reference: $\mathrm{BCCH}<1 \mathrm{~h}$} \\
\hline BCCH 1-2h & $-1.53(-5.21,2.15)$ & 0.41 & $-2.13(-5.80,1.55)$ & 0.25 & $0.09(-4.52,4.70)$ & 0.97 \\
\hline $\mathrm{BCCH}>2 \mathrm{~h}$ & $-3.91(-7.92,0.10)$ & 0.06 & $-3.58(-7.53,0.37)$ & 0.08 & $-7.24(-11.86,-2.63)$ & 0.003 \\
\hline Community & $-1.30(-3.94,1.34)$ & 0.33 & $-0.47(-3.13,2.19)$ & 0.73 & $-0.87(-4.09,2.35)$ & 0.59 \\
\hline \multicolumn{7}{|c|}{ Reference: Community } \\
\hline $\mathrm{BCCH}<1 \mathrm{~h}$ & $1.30(-1.34,3.94)$ & 0.33 & $0.47(-2.19,3.13)$ & 0.73 & $0.87(-2.35,4.09)$ & 0.59 \\
\hline BCCH 1-2h & $-0.23(-3.90,3.44)$ & 0.90 & $-1.65(-5.30,1.99)$ & 0.37 & $0.96(-3.71,5.63)$ & 0.68 \\
\hline $\mathrm{BCCH}>2 \mathrm{~h}$ & $-2.61(-6.61,1.39)$ & 0.20 & $-3.10(-7.03,0.82)$ & 0.12 & $-6.37(-11.04,-1.70)$ & 0.008 \\
\hline
\end{tabular}

*Adjusted for age and income.

** The model was not adjusted for any other variables because no other variables were significant at a-priori cut-off of 0.15 levels of significance in the unadjusted analysis to be eligible for the adjusted analysis.

This article is protected by copyright. All rights reserved. 
Table 4: Group differences in mean $\mathrm{HbA}_{1 \mathrm{C}}(\% ; \mathrm{mmol} / \mathrm{mol})$ between tertiary groups $(\mathrm{BCCH}$; stratified by travel time) and community group from linear regression models

$\begin{array}{lccc}\text { Unadjusted difference } & \text { p-value } & \text { Adjusted difference } & \text { p-value } \\ \% ; \mathrm{mmol} / \mathrm{mol}(95 \% \mathrm{CI}) & & \% ; \mathrm{mmol} / \mathrm{mol}(95 \% \mathrm{CI}) * & \end{array}$

Reference: $\mathrm{BCCH}<1 \mathrm{~h}$

$\begin{array}{lllll}\text { BCCH 1-2h } & 0.28 ; 3.1(-0.18,0.73 ;-2.0,8.0) & 0.23 & 0.25 ; 2.7(-0.20,0.71 ; 2.2,7.8) & 0.27\end{array}$

$\mathrm{BCCH}>2 \mathrm{~h} \quad 0.76 ; 8.3(0.26,1.25 ; 2.8,13.7) \quad 0.003 \quad 0.65 ; 7.1(0.15,1.15 ; 1.6,12.6) \quad 0.01$

Community $\quad 0.27 ; 3.0(-0.06,0.59 ;-0.7,6.4) \quad 0.11 \quad 0.13 ; 1.4(-0.21,0.46 ;-2.3,5.0) \quad 0.46$

Reference: Community

ВССH $<1 \mathrm{~h} \quad-0.27 ;-3.0(-0.59,0.06 ;-6.4,0.7) \quad 0.11 \quad-0.13 ; 1.4(-0.46,0.21 ; 5.0,2.3) \quad 0.46$

BCCH 1-2h $\quad 0.01 ; 0.1(-0.44,0.47 ;-0.48,5.1) \quad 0.96 \quad 0.13 ; 1.4(-0.33,0.59 ;-3.6,6.4) \quad 0.58$

$\mathrm{BCCH}>2 \mathrm{~h} \quad 0.49 ; 5.4(-0.00,0.98 ;-0.0,10.7) \quad 0.05 \quad 0.52 ; 5.7(0.02,1.02 ; 0.2,11.1) \quad 0.04$

*Adjusted for age and parental education

BCCH: British Columbia Children's Hospital; $\mathrm{h}=$ hour
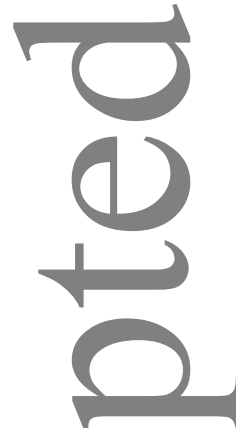

This article is protected by copyright. All rights reserved. 


\section{LEGEND:}

Figure 1: Differences in caregiver reported barriers to care between tertiary groups $(\mathrm{BCCH}$;

stratified by travel time) and community group
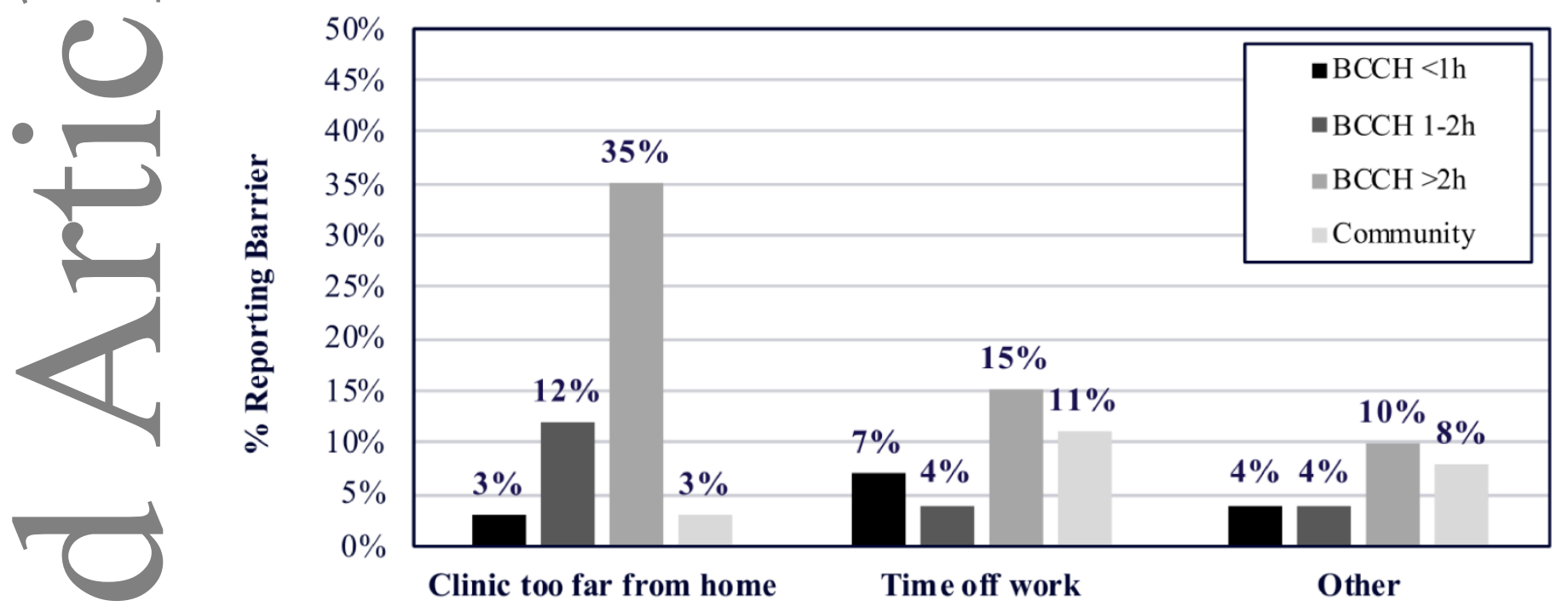

This article is protected by copyright. All rights reserved. 


\section{Supplemental Material}

\section{Barriers to Care Survey Question}

What are some of the reasons that make it difficult for you to take your child to his/her diabetes clinic appointments? (select all that apply)

The clinic is too far from where I live

There is no close public transportation close to where I live

I can't afford the transportation costs

Parking at the clinic is too expensive

I work long hours and don't have time to take my child to his/her appointments

I can't take the time off work to take my child to his/her diabetes clinic appointment

$\square$ I feel the diabetes clinic appointment isn't a good use of my time

$\square$ It's hard to find someone to watch my other children when I take my child to his/her appointments

Other (please specify) 